* Andre Mendes da Fonseca Ferraz, Mestre em Sociologia e Direito pelo Programa de PósGraduação em Sociologia e Direito da Universidade Federal Fluminense - PPGSD/UFF. Email: andrefferraz0348@ gmail.com

** Ronaldo Joaquim da Silveira Lobão, Professor do Programa de Pós-Graduação em Sociologia e Direito da Universidade Federal Fluminense . Bacharel em Ciências Sociais (1997), e Mestre em Antropologia pela Universidade Federal Fluminense (2000) e doutor em Antropologia pela Universidade de Brasília. E-mail: ronaldolobao@yahoo.com.br

\section{O caso dos Caiçaras da praia de Trindade: aproximações honnethianas para uma perspectiva intercultural de direitos humanos, justiça social e cidadania}

\author{
The case of Caiçaras of beach of \\ TRINDADE: APPROACHES HONNETHIANAS WITH \\ CROSS-CULTURAL PERSPECTIVE OF HUMAN \\ RIGHTS, CITIZENSHIP AND SOCIAL JUSTICE
}

Andre Mendes da Fonseca Ferraz *

Ronaldo Joaquim da Silveira Lobão **

Resumo: Objetivando caracterizar os Caiçaras da praia de Trindade e os processos de criação e gestão do PARNA da Bocáina; analisar, por aproximação crítica, pela teoria honnethiana, as reivindicações desses Caiçaras e; identificar os elementos possibilitadores de percepção intercultural e do reconhecimento das pretensões dessa comunidade; este estudo teórico, sustentou-se na técnica de análise do conteúdo proposicional dos discursos, em Bardin, para inferir das estruturas argumentativas o "universo de referência", questões e ações dos atores sociais; e identificou as condições e elementos interculturais, para percepção das pretensões desses Caiçaras, em termos de direitos humanos, justiça social e cidadania.

Palavras-Chave: Direitos Humanos Culturais. Comunidades Tradicionais. Caiçaras da praia de Trindade. Direitos Humanos. Justiça Social. Cidadania em sociedades multiculturais.

Abstract: Aiming to characterize the Caiçaras of beach of Trindade and the processes of creation and management of PARNA bocaina; analyze, with a critical approach, the theory honnethiana, about the Caiçaras claims; identify enablers elements of intercultural awareness and recognition of the claims of this community, this theoretical study, was sustained in the technical of analysis of the propositional content of speeches, in Bardin, to infer of the argumentative structures the "reference population", issues and actions of social actors, and Identified the conditions, and intercultural elements, for perception of these claims Caiçaras in terms of human rights, social justice and citizenship.

Keywords: Human Rights Cultural. Traditional Communities. Caiçaras of beach of Trindade. Human Rights. Social Justice. Citizenship in multicultural societies. 


\section{INTRODUÇÃO}

O interesse deste estudo surgiu de investigações sobre relações sociais interculturais em sociedades de grande assimetria social e diversidade cultural como a brasileira, na qual as tensões e conflitos levam ao questionamento a cerca da participação social nas decisões legislativas e administrativas, sobretudo dos modelos administrativos de gestão e decisão compartilhadas com as populações tradicionais residentes em Unidades de Conservação, bem como sobre as condições culturais para o reconhecimento das pretensões dessas comunidades, em termos de direitos humanos, justiça social e cidadania.

Ao se analisar o contexto histórico das estratégias e políticas de criação e gestão de áreas protegidas, em seus regimes jurídicos especiais para proteção de recursos naturais, adotados no Brasil desde o período da colonização, é possível perceber que sua lógica tem contemplado duas tradições distintas: (1) a noção de conservação da natureza, voltada para o manejo dos recursos e uso sustentável, com participação da sociedade civil paralela à lógica da preservação, típica dos Estados Europeus e exportada para a comunidade intelectual das colônias, por meio de suas universidades, tais como as de Coimbra e Lisboa (Portugal) e a de Paris (França); (2) a noção de preservação da natureza, voltada para a proteção de belezas cênicas naturais e monumentos de valor histórico e artístico, segundo ideologia preservacionista e o movimento internacional de Criação de Parques Nacionais no modelo do Parque norteamericano de Yellowstone (1872). No Brasil, a noção de natureza foi incorporada no período republicano, e, consolidada na Constituição de 1934, a partir dessa, a natureza passou a figurar como patrimônio nacional a ser preservado pelo Estado, segundo a política de desenvolvimento nacional; e posteriormente, no período da ditadura militar (1964-1984), passou a ser pensada como importante instrumento geopolítico (MEDEIROS; IRVING; GARAY, 2006, p. 15-22).

Para o modelo preservacionista, a única forma de proteger a natureza e a vida selvagem (wildnerss) era afastá-la do ser humano, por meio de "ilhas" onde este pudesse admirá-la e reverenciá-la (DIEGUES, 2008, p. 17). Esse neomito da natureza intocada foi transposto para o Brasil, cuja situação ecológica, social e cultural é totalmente diversa. O Brasil possui grande variedade de modos de vida diferenciada, com mais de duas centenas de línguas diferentes, comunidades de quilombo, populações ribeirinhas, extrativistas, pescadores artesanais, e etc., todas portadoras de cultura própria/tradicional, mitos e relações com o mundo natural distintos das sociedades urbano-industriais (DIEGUES, 2008, p. 18). 
Diegues (2008, p. 13) critica os processos e o modelo preservacionista adotados para criação de áreas naturais protegidas, cuja implantação, sobretudo no Brasil, tem implicado limitações nos modos tradicionais de vida e até mesmo grande número de expulsões dos espaços que tradicionalmente ocupam ou utilizam.

O mesmo autor sustenta que quase nunca os governos avaliam os impactos da criação de Parques sobre o modo de vida dos moradores locais, os quais, muitas vezes, tinham sido os primeiros responsáveis pela preservação das áreas naturais. Que a própria expulsão desses moradores tem contribuído ainda mais para a degradação das áreas de parques, uma vez que, frequentemente ficam desprotegidas, por falta de recursos para promover sua fiscalização (DIEGUES, 2008, p. 22). E que a "participação" das populações tradicionais no estabelecimento dos parques, não "passa de cortina de fumaça" para responder a certas demandas internacionais para financiamento que consideram o envolvimento dessas populações como fator positivo para o êxito do empreendimento. Pois, na realidade, as autoridades governamentais geralmente nem sempre veem com bons olhos a organização das populações que ainda se encontram em áreas de parques ou que foram reassentadas em suas zonas de amortecimento (DIEGUES, 2008, p. 23).

Essa situação tem trazido inúmeros problemas de caráter político, econômico, social e cultural, pois a mesma não se reduz à simples "conservação do mundo natural" e mesmo à proteção da biodiversidade (DIEGUES, 2008, p. 20).

No Brasil, dentre as diversas categorias de manejo de Áreas Protegidas, destaca-se a de Parque Nacional, criada pelo Código Florestal de 1934 (Decreto N. ${ }^{\circ} 23.793$ de 23 de janeiro de 1934) como categoria de manejo que melhor representa a estratégia de criação de espaços naturais esvaziados da presença humana (CONTI, 2011, p. 9-29).

O processo histórico de criação de Parques Nacionais no Brasil, iniciado com a criação do Parque Nacional de Itatiaia em 1937, resultou de diferentes disputas e arranjos políticos, influenciados principalmente por: (1) uma cultura hegemônica de dicotomização sociedade-natureza; (2) uma lógica preservacionista de criação de áreas protegidas como categorias de manejo nas quais resta proibido o uso direto dos recursos naturais, em seu interior ou entorno; e (3) finalidade de "oferecer lazer às populações urbanas" (CONTI, 2011, p. 9-29). 
O que fez com que critérios como beleza cênica, facilidade de acesso e a possibilidade de visitação de massa determinassem a escolha de áreas para a criação de Parques Nacionais brasileiros. Esta, por sua vez, se caracterizou por: (1) priorização da região sudeste, sobretudo de áreas que envolviam problemas fundiários complexos e recursos naturais desgastados, não acompanhando uma distribuição regional ou ecossistêmica equilibrada; (2) preservação da fauna e da flora, sem contemplar a dinâmica complexa das relações sociais no interior ou entorno desses espaços; (3) supressão de direitos à propriedade e uso da terra por parte das populações locais, principalmente as tradicionais, bem como restrição e criminalização de suas práticas habituais de uso dos recursos naturais desses espaços, o que dificulta a reprodução sociocultural desses grupos sociais, e; (4) criação e implementação autoritária e não negociada desses espaços pelo Estado perante os diferentes grupos sociais locais, sobretudo quanto à demarcação desses espaços e o modelo de proteção a ser adotado (CONTI, 2011, p. 9, 16-171).

O processo histórico de tomada unilateral de decisões sobre criação e modelos de gestão dessas áreas tem gerado tensões e conflitos quanto à implementação de políticas públicas, pela desconsideração dessas populações locais nos processos decisórios e modelos de conservação, que para obterem legitimação social, dependem da capacidade dessas mesmas populações atribuírem ou não validez, enquanto destinatárias dessas decisões (CONTI, 2011, p. 9-33).

Esses conflitos são agudizados pela resistência das instituições governamentais em reavaliar seus próprios modelos centralizados de proteção e de decisão, e pela perspectiva dos atores institucionais de estarem limitados à aplicação formal da lei e procedimentos gerenciais (CONTI, 2011, p. 9-179). Além disso, dificuldades na integração sistemática e atuação conjunta das instituições governamentais nas esferas federal, estadual e municipal, no local de inserção dessas áreas, têm gerado conflitos entre suas diferentes políticas públicas. Tais atuações segmentadas e desarticuladas acabam por se distanciar da realidade local (IRVING, 2002, p. 60 apud CONTI, 2011, p. 52-53).

Esse conjunto de posturas e limitações institucionais tem limitado a perspectiva das instituições governamentais acerca da importância da gestão compartilhada com as comunidades locais na tomada de decisões nas áreas protegidas. No entanto, tal compartilhamento poderia contribuir para a prevenção de conflitos socioambientais e fundiários, e implicaria levar em conta a percepção pelas populações locais acerca dessas áreas protegidas como patrimônio coletivo 
e não como bem de domínio do poder burocrático-estatal. A visão contrária é que desestimula seu engajamento e participação na efetivação dessas decisões (CONTI, 2011, p. 53-159).

Pode-se perceber a relevância dessa problemática ao analisá-la na perspectiva de Herculano (2006, p. 127-128) quanto à cidadania, para quem esta possui uma referência especial construída pela relação do ser humano com um determinado espaço social que lhe dá identidade. Dessa forma, a ideia de Cidadania engloba os conceitos de identidade sociocultural, vínculos de pertencimento, participação, laços de solidariedade e herança cultural, além de organização jurídico-legal.

Herculano (2006, p. 373-385), ao analisar as propostas de sustentabilidade ambiental e seu componente social, ressalta a importância de alguns princípios da Declaração do Rio de Janeiro sobre o Meio Ambiente e Desenvolvimento da ECO/92 à legitimidade das decisões: os seres humanos como centro das preocupações com o desenvolvimento sustentável ( $1^{\circ}$ princípio); a participação social de todos os interessados, devendo o Estado garantir informação à disposição de todos, promover sensibilização e oportunidade de participação nos processos decisórios ( $10^{\circ}$ princípio); a importância da valorização e participação social das comunidades tradicionais e locais no planejamento de políticas públicas e projetos de desenvolvimento sustentável adequados à singularidade biológica e sociocultural do ecossistema local, bem como à sua efetivação, devido a seus conhecimentos sobre o ecossistema local, suas práticas tradicionais, e à dimensão local das sociabilidades humanas $\left(22^{\circ}\right.$ princípio $)$. $\mathrm{E}$ denuncia, como uma das raízes evidentes da crise ambiental o eco-tecnicismo/ tecnocentrismo, que busca estabelecer padrões universais homogeneizantes meramente técnicos de sustentabilidade e desenvolvimento percebidos no planejamento ambiental no Brasil (HERCULANO, 2006, p. 387-397).

Lobão (2010), conclui que na raiz dos conflitos socioambientais envolvendo as "populações tradicionais" encontram-se indícios da manipulação de categorias caracterizadoras desses grupos (tempo e espaço, bem como natureza e cultura) e de categorias jurídicas do direito ambiental e fundiário, tal como "Meio Ambiente", "Desenvolvimento Sustentável", e "Unidades de Conservação", para o controle de suas demandas, tratadas burocraticamente pelo Estado como conflitos a administrar. E critica a atuação do Ministério do Meio Ambiente, que tem sido limitada por um sistema de convênios, acordos e financiamentos internacionais, que resultam na perda da autonomia local para definir parâmetros do bem-viver e Desenvolvimento Sustentável, bem como as Áreas Protegidas 
(Terras Indígenas, Terras de Quilombo e Unidades de Conservação), utilizados para conformar culturas particulares a modelos exógenos, ignorando-se a inexistência, no território brasileiro, de espaços ambientais que não façam parte da história de vida de algum grupo social (LOBÃO, 2010, p. 23-230).

Para esse autor, o Sistema Nacional de Unidades de Conservação SNUC introduziu uma nova estrutura de poder de enunciação e controle sobre essas populações, na qual: (1) o conhecimento tradicional ficou subordinado ao conhecimento científico, supostamente dotado de maior grau de previsibilidade, e aos paradigmas do "Desenvolvimento Sustentável"; (2) o uso de recursos naturais renováveis, consagrado pelo saber tradicional das populações tradicionais, foi substituído por práticas sustentáveis de "Manejo" que visam apenas garantir a perenidade dos recursos e não desses grupos; (3) as relações experimentadas com os espaços conhecidos e singulares foram esvaziadas de sentimentos concretos e, em nome da "Conservação da Biodiversidade", transformados em ideais e espaços difusos e universais, ou categorias abstratas como "Meio Ambiente" e "Unidade de Conservação"; (4) a justiça social passou a ser parametrizada por aspectos econômicos a partir da vertente "sustentável" de sua atividade economicamente viável; (5) a diversidade cultural sublimada mediante sua conformação a um padrão uniforme de identidades coletivas adequadas à conservação do Meio Ambiente, em Áreas Protegidas sob o controle do Estado (LOBÃO, 2010, p. 13-56).

Assim, o autor consegue perceber limitações à efetivação do princípio da democracia, vinculado à valorização da participação igualitária, autodeterminação e fortalecimento de sua "capacidade de agência", impostas pelos limites estreitos do princípio da conservação ambiental e pelos saberes que podem atestá-la. Nessa situação, até mesmo a escolha das identidades coletivas, mesmo que pelo viés da autodeterminação tem ocorrido entre margens que marcam a associação das identidades pretendidas, construídas na esfera micro, ou das categorias identitárias distintas assumidas na esfera meso, compatíveis com as práticas ambientais sustentadas e ecossistemas merecedores de proteção (LOBÃO, 2010, p. 248).

Por isso, conclui pela necessidade de se rediscutir a própria ideia de cidadania, e as formas de participação e empoderamento, percebendo que esta não pode ser construída sem os iguais direitos políticos e socioculturais conexos aos direitos ambientais, sobretudo direitos políticos ativos de participação direta dos grupos sociais nas decisões legislativas e no planejamento das políticas e projetos ambientais de bem-estar e desenvolvimento sustentável. Sem isto, 
correr-se-ia o risco de uma cidadania tutelada, de violação de direitos legais e ilegitimidade das decisões (LOBÃO, 2010, p. 218-245).

Nesse mesmo contexto dos problemas enfrentados pelas comunidades tradicionais nos processos de criação e gestão de unidades de conservação, participação nas decisões legislativas e administrativas sobre os modelos administrativos de gestão e decisão, e condições para o reconhecimento de suas pretensões culturais, surge a preocupação central deste estudo. Trata-se, aqui, do caso da comunidade dos Caiçaras da praia de Trindade, no Município de Paraty, Estado do Rio de Janeiro, situada no segmento do Mosaico da Bocáina, de interseção entre o Parque Nacional da Serra da Bocáina (PNSB), modelo de Unidade de Conservação cujo plano de manejo inadmite a permanência dessa comunidade em sua área tradicionalmente ocupada e utilizada, bem como a continuidade das atividades que tradicionalmente realizam.

Assim, de acordo com a realidade de grande assimetria social e diversidade cultural como a brasileira, tendo como referência o caso concreto da comunidade Caiçara da praia de Trindade, a questão central aqui trabalhada é: quais as condições culturais para o reconhecimento das pretensões dessa comunidade, em termos de direitos humanos, justiça social e cidadania?

Como natural desdobramento da questão norteadora, este estudo teve por objetivos: (1) identificar e caracterizar os Caiçaras da praia de Trindade e os processos de criação e gestão do Parque Nacional da Serra da Bocáina; (2) analisar, numa aproximação crítica pela teoria honnethiana as reivindicações dos Caiçaras da praia de Trindade, não apenas pela perspectiva do reconhecimento jurídico estatuído pela ordem vigente, mas pelos sentimentos e expectativas morais que lhes tem sido culturalmente ignorados, tracejados, segundo material secundário de pesquisa selecionado; e (3) identificar os elementos pelos quais se pode ampliar a percepção e o reconhecimento das pretensões dessa comunidade, em termos de direitos humanos, justiça social e cidadania.

Dessa forma, o recorte desta pesquisa é a Comunidade Tradicional Caiçara da Praia de Trindade e suas interações sociais no PNSB, categoria Unidade de Conservação de proteção integral criada arbitrariamente segundo imperativos sistêmicos e cujo plano de manejo inadmite os Caiçaras da Praia de Trindade em sua área tradicionalmente ocupada e utilizada, bem como as atividades que tradicionalmente realizam.

Quanto ao aspecto metodológico, trata-se de estudo teórico, descritivo, bibliográfico, documental, exploratório, com foco explicativo. Fundamentado 
na técnica de análise de conteúdo de Bardin (2011) pela discussão de publicações jurídicas, obras teóricas de autores nacionais e estrangeiros, bem como em documentos de fé pública nacional e internacional, com vistas no alcance dos objetivos formulados e contemplando a discussão a respeito das variáveis identificadas que agem diretamente sobre o fenômeno estudado.

\section{CARACTERIZAÇÃO DOS CAIÇARAS DA PRAIA DE TRINDADE}

A palavra caa-içara é de origem tupi-guarani e faz referência às estacas colocadas em torno das aldeias e à pesca indígena por meio de galhos de árvores fincados na água para cercar o peixe. Com o tempo, passou a referenciar as populações de pescadores artesanais que se constituíram a partir do cruzamento entre indígenas, portugueses e negros nos litorais sul e sudeste brasileiros, bem como às palhoças por eles construídas nas praias para abrigar suas canoas e apetrechos de pesca (ABIRACHED, 2011; ADAMS, 2000).

Adams (2000) critica a caracterização romântica das comunidades caiçaras como pescadoras, tradicionais, rústicas, isoladas, auto-suficientes, primitivas e dotadas de um referencial marítimo. Para essa autora, a formação das comunidades caiçaras só pode ser entendida numa perspectiva diacrônica do contexto da ocupação do litoral brasileiro e dos ciclos econômicos vividos pela região sul/sudeste, segundo a qual essas comunidades caiçaras eram mais complexas, dinâmicas e variadas internamente do que se costuma escrever.

Essa autora ainda critica a falta de uma abordagem ecológica séria e de uma base empírica confiável na literatura, em cujos discursos tendem a vincular a imagem dos caiçaras ao mito do "bom selvagem", com sofisticados conhecimentos de manejos de pesca, desconsiderando o fato de que um maior ou menor domínio e conhecimento de alguns tipos de pesca e dos ecossistemas significa apenas que essas populações têm uma boa percepção do meio em que vivem, decorrente de fatores históricos e geográficos, bem como as características ecológicas locais que diferenciam essas comunidades entre si, o que não basta para afirmar que garantam a conservação do meio ambiente (ADAMS, 2000).

Durante o processo de colonização dos grupos indígenas que viviam na região de Paraty, parte dos índios se tornou escravos nas plantações de cana e outra parte fugiu mais pra dentro da mata. Com a fundação da cidade de 
Paraty em 1531, os indígenas passaram a dividir o espaço com os caiçaras (ABIRACHED, 2011, p. 37).

A emancipação de Paraty como município ocorreu em 1667, durante o período do ouro das minas gerais, Paraty foi importante entreposto comercial (séculos XVII e XVII), embora sua base econômica local fosse a agricultura camponesa das roças caiçaras itinerantes (ABIRACHED, 2011, p. 37).

Já os séculos XVIII e XIX, em Paraty, foram marcados pela economia açucareira, representada pela presença de inúmeros engenhos, e cultivo de café e cana-de-açúcar nas fazendas pelo trabalho escravo de milhares de negros africanos. Mas, com a abolição da escravatura, ampliaram-se os números de roças familiares, os negros buscaram terras para praticarem agricultura. As atividades agrícolas na região passaram a ser a de subsistência de caiçaras e escravos, e a exportadora de fazendeiros (ABIRACHED, 2011, p. 37-38). Nesses locais, a agricultura de subsistência servia como retaguarda econômica dos grandes engenhos, garantindo a sobrevivência das populações locais (ADAMS, 2000, p. 17).

Ao longo dos ciclos econômicos os caiçaras juntamente com os indígenas e quilombolas foram sendo expulsos de lugar a lugar até que indígenas e quilombolas restaram nos sertões, áreas rurais e serranas, enquanto os caiçaras nas áreas costeiras próximas ao mar (ABIRACHED, 2011, p. 38-39).

Isso acarretou numa mudança no modo de ser caiçara, pela preponderância da pesca artesanal, empregando a rede de espera, o cerco flutuante, a tarrafa, o pesqueiro, o covo, o mergulho, o tresmalho, o currico, o puçá (BRASIL, 2004). A praia passou a constituir-se no centro da vida caiçara, e a querência e o afeto ao lugar, referencias dos sentimentos de pertencimento ao grupo e de distinção de outros grupos caiçaras, além de ponto de articulação com o mundo exterior (ADAMS, 2000).

As casas caiçaras eram de pau-a-pique, telhado de sapê, chão de terra batida, alinhadas com a frente para o mar, com paredes brancas contrastando com o verde escuro das árvores no entorno, refletindo-se nos ensolarados na água do mar (ADAMS, 2000). Essas casas não tinham cercas e cada família sabe dos limites de seus terrenos e respeita os dos demais (ABIRACHED, 2011).

Os Caiçaras utilizam recursos naturais específicos daquela região para sua alimentação, principalmente de peixe, pirão e banana, e ainda de madeira branca do Jacatirão para construção de casas e Timbiuva e Ingá Flexa para construção de canoas. Utilizam ainda como ervas medicinais a Cutiabeira, Maria 
Preta, Santa Maria, o Broto de goiaba e de Pitanga (BRASIL, 2004). E detêm especial conhecimento do bioma da Mata Atlântica, sobre o ambiente biofísico, a ecologia da fauna e da flora, dentre outros aspectos fundamentais desse ecossistema. Além desses, sobre as condições da natureza fundamentais para a pesca tais como o tempo, os tipos de vento, de nuvem, das marés e das correntes marítimas, as fases e a posição da Lua.

Eles produzem farinha de mandioca, farinha de coco, cuscuz, pichê de milho, o famoso azul marinho (peixe ensopado com banana verde). Além de fabricação artesanal de balaios com taquaras, panelas de barro e tipitis (instrumentos musicais de corda) utilizados nas festividades religiosas e nas danças. Esculpem remos e tecem redes de pesca. Moram em casas de madeira, sendo cada peça feita com uma madeira específica e, mais recentemente, de tijolo com telha de barro (BRASIL, 2004, p. 103).

A tradição caiçara se constitui por sistemas de cognição do mundo, saberes, práticas e valores associados às especificidades do ambiente natural, por tecnologias patrimoniais e relações sociais marcadas pela reciprocidade, e por simbologias, músicas e danças associadas à periodicidade das atividades de terra e de mar, realizadas e transmitidas às novas gerações pela oralidade (ABIRACHED, 2011).

Percebe um sincretismo religioso entre práticas tradicionais de parteiras e curandeiros e uma difusão de festas religiosas da igreja católica, em que cada comunidade tinha seu padroeiro e, mais recentemente, a proliferação de igrejas protestantes com prejuízos ao folclore caiçara (ADAMS, 2000; ABIRACHED, 2011).

Com o novo ciclo econômico do turismo, no século XX, esse processo foi agravado pela redescoberta do litoral sudeste pela classe média, construção da Estrada Paraty-Cunha ligada à Rodovia BR-116 (eixo RJ - SP) que aumentou os interesses imobiliários e pela resignificação da Mata Atlântica pelos ecologistas, essas comunidades começam a perder, cada vez mais, suas terras pela força econômica ou coercitiva e a terem definitivamente alterados seus modos de vida (ABIRACHED, 2011).

Para Adams (2000), essas comunidades caiçaras eram constituídas em sua maioria por lavradores-pescadores, até meados do século XX, mas com a introdução do cerco, do barco a motor e da pesca embarcada e seletiva, passaram a dedicar uma parte cada vez maior à pesca, restando apenas uma agricultura incipiente em torno da habitação. A pesca era uma atividade essencialmente masculina, exceto no caso da pesca da tainha, forma de pesca coletiva (arrasto 
de praia) de grande importância para as comunidades caiçaras, sobretudo como fator de integração social. A pesca era complementada pela coleta de caranguejos, ostras, moluscos (ADAMS, 2000).

As áreas historicamente utilizadas pelos Caiçaras de Trindade para sua pesca artesanal tem sido a área marinha que vai desde a Praia do Meio até a praia do Caxadaço e seu costão rochoso, atualmente abrangida pelo Parque Nacional da Serra da Bocáina - PNSB. Esses Caiçaras utilizam-se de redes de cerco que são monitoradas pelos pescadores por meio de um tipo de barco chamado "voadeira", mas quando o mar está "grosso, picado", são utilizadas canoas ao invés de voadeiras. Jovens pescadores trabalham de forma cooperativa. E o pescado, conservado em isopores com gelo, é vendido a atravessadores de Paraty, restaurantes da Vila, e consumido pelos pescadores ou distribuído para amigos de comunidades vizinhas (ABIRACHED, 2011).

As primeiras famílias dos Caiçaras da praia de Trindade ocupavam a Praia do Caxadaço, no interior do PNSB, segundo relato de moradores locais. Com a pressão imobiliária, uma parte dessas famílias caiçaras migrou para outros municípios, mas a maior parte foi morar na área da Vila e da Praia de Fora, hoje abrangidas pela APA Cairuçu, fora área hoje abrangida pelo PNSB (ABIRACHED, 2011).

Nessas localidades foram criados o Parque Nacional da Serra da Bocáina - PNSB, pelo Decreto Federal n. ${ }^{\circ}$ 68.172/1971, e a Área de Preservação Ambiental -APA Cairuçu, pelo Decreto n. ${ }^{\circ} 89.242 / 1983$, sem qualquer consulta às populações locais.

Com o advento da Lei n. ${ }^{\circ}$ 9.985/2000 que instituiu o Sistema Nacional de Unidades de Conservação - SNUC, o PNSB foi transformado em Unidade de Conservação de proteção integral, tipo que impõe pelos planos de manejo restrição de uso dos recursos naturais às suas atividades nele realizadas, colocando em risco a permanência das populações que as ocupem. Já a APA Cairuçu foi transformada em Unidade de Uso Sustentável, tipo que permite compatibilizar a conservação da natureza com o uso sustentável de parcela dos seus recursos naturais pelas populações locais.

\section{OS CAIÇARAS E O PARQUE NACIONAL DA SERRA DA BOCÁINA - PNSB}

Na primeira fase do processo demarcatório do PNSB, a aproximação de autoridades do Instituto Brasileiro de Meio Ambiente e dos Recursos Naturais 
Renováveis - IBAMA foi impositiva e autoritária, e teve como referencial a ordem judicial de reintegração de posse e despejo da comunidade. E, os Caiçaras de Trindade buscaram garantir judicialmente sua pretensão ao reconhecimento de seu direito de continuar a ser quem são, no lugar que fazem e os faz reciprocamente, ou seja, de permanecer na praia de trindade, área do PNSB, por meio de ação de usucapião ${ }^{1}$.

Os Caiçaras de Trindade organizaram-se socialmente em torno da "Associação de moradores nativos e originários da Praia da Trindade", como um grupo de indivíduos da própria comunidade que funcionava como um conselho que delibera sobre a organização da produção, resolução de conflitos e demais interesses intra e extracomunitários (BRASIL, 2004).

Gradativamente, numa segunda fase do processo demarcatório, cujo referencial foi a chegada e atuação do Instituto Chico Mendes de Conservação da Biodiversidade - ICMBio, a situação de conflito foi se tranquilizando pelos canais de comunicação restabelecidos e a tensão se internalizando pelos procedimentos de discussão e mediação implantados, em reuniões com lideranças comunitárias e audiências públicas locais ${ }^{2}$.

Nesse processo, parece ter sido relevante, ao menos pelo que foi possível observar pessoalmente em 2009, pelo autor do presente estudo, ter sido toda aquela paixão demonstrada pelos Caiçaras por Trindade o sentimento que provocou grande sensibilização e solidariedade dos agentes do ICMBio.

Em 22 de julho de 2010, ocorreu o improvimento de Recurso Especial N. ${ }^{\circ} 1.091 .438$ - RJ ao STJ, da decisão inicial de usucapião pela imprescritibilidade das áreas suscitadas pelos Caiçaras de Trindade, na ação de usucapião por eles promovida, situadas em terreno de marinha e no PNSB.

O plano de manejo do PNSB, Portaria IBAMAN. $.^{\circ} 112 / 2002$, estabeleceu proibições da agricultura e da caça, e dessa forma a pesca passaria a se constituir a principal atividade econômica dos Caiçaras, além do artesanato e do turismo que complementam a alimentação e a renda familiar (BRASIL, 2004, p.103).

Mas, o plano de manejo do PNSB ao estabelecer as praias do Caxadaço e do Meio, a piscina natural do Caxadaço, bem como as trilhas do Rochedo Cabeça do Índio e da cachoeira Pedra que Engole, como parte da Zona de Uso Extensivo destinada à educação ambiental e recreação, não previu a atividade de pesca realizada pelos Caiçaras de Trindade (ABIRACHED, 2011).

\footnotetext{
${ }^{1}$ Segundo relatos de Caiçaras da Trindade, colhidos em conversação com caiçaras na praia da trindade em 2009.

${ }^{2}$ Segundo relatos de Caiçaras da Trindade, colhidos em conversação com caiçaras na praia da trindade em 2009.
} 
Além disso, o plano de manejo do PNSB estabeleceu a desapropriação dos imóveis pertencentes aos moradores e a retirada daqueles que se estabeleceram ilegalmente na área, e no caso das famílias Caiçaras da praia de Trindade, reassentamento sem a previsão de zona de ocupação temporária, o que contraria a diretiva do roteiro metodológico de planos de manejo de parques (ABIRACHED, 2011, p.112).

Dessa forma, as duas famílias caiçaras que ainda residem na Praia do Caxadaço, embora desejem manter-se no local, não têm sequer a posse assegurada e veem-se diante da possibilidade de serem reassentadas em outra área, fora do PNSB (ABIRACHED, 2011).

O Conselho Consultivo do PNSB foi instituído somente em setembro de 2010, mediante a Portaria ICMBio N..$^{\circ}$ 103/2010, e concretizado em dezembro do mesmo ano quando a instalação da Câmara Técnica de Uso Público das Zonas de Uso Extensivo para visitação turística (ABIRACHED, 2011).

Os Caiçaras de Trindade têm reclamado também contra a pesca industrial e das práticas predatórias de arrasto, bem como do processo de ocupação, uso desordenados do solo e a pressão fundiária sobre as terras que ocupam e usam tradicionalmente, exercidos pelos setores econômicos, imobiliário e do turismo (ABIRACHED, 2011).

Segundo o Decreto de criação da APA Cairuçu, contando com uma área continental de $338 \mathrm{~km} 2$, vai desde as margens da zona urbana de Paraty/RJ até a divisa municipal com Ubatuba/SP e áreas insulares ao longo 63 ilhas nas enseadas de Paraty, seu objetivo é a proteção do ambiente natural que abriga espécies endêmicas e ameaçadas de extinção, sistemas hidrológicos, paisagens de grande cênica e, ainda, as comunidades caiçaras (ABIRACHED, 2011).

O processo de elaboração do plano de manejo da APA Cairuçu teve início em 1999, a partir de uma cooperação técnica entre Instituto Brasileiro de Meio Ambiente - IBAMA, Instituto Estadual de Florestas - IEF/RJ, Prefeitura de Paraty e ONG SOS Mata Atlântica. O plano foi instituído pela Portaria Ibama N. 28 e vem sendo implementado desde 2007 pelo ICMBio (ABIRACHED, 2011, p. 51).

O zoneamento da APA Cairuçu é a regra geral para os tipos de uso (residencial, comercial, comunitário e de lazer), a ser complementado pelo plano diretor por meio de um microzoneamento que estabeleça regras edilícias de padronização urbanística e ordenamento das ocupações existentes, bem instrumentos de controle e monitoramento de novas construções (ABIRACHED, 2011). 
A delimitação nos mapas do espaço de ocupação e uso caiçara na APA do Cairuçu pelo plano diretor foi requerida pelas associações de moradores e pescadores de Trindade durante a reunião sobre o tema realizada no dia 21/10/2010. Ocasião, em que foi lida e apresentada à prefeitura de Paraty e à equipe da UERJ numa carta expositiva dos motivos do pedido (ABIRACHED, 2011, p. 115). Mas, foi proposto novo projeto de lei do plano diretor de Paraty que em seu art. 283 trata trindade como "núcleo urbano isolado" a ser objeto de microzoneamento específico para definir áreas urbanas consolidadas e de expansão, bem como os parâmetros para parcelamento, uso e ocupação (ABIRACHED, 2011, p. 113).

Assim, o plano diretor municipal deveria delimitar o espaço de uso e ocupação caiçara, mas o fato de o município de Paraty possuir mais de $80 \%$ de seu território abrangido por essas Unidades de Conservação federais e estaduais e a pressão dos setores econômicos imobiliário e turístico, tem retardado essa delimitação no plano diretor, das Zonas de Expansão das Vilas Caiçaras (de moradia) e as Zonas de Conservação Costeira, de manejo múltiplo pelos Caiçaras, instituídas pelo plano de manejo da APA Cairuçu, e tendem a agravar os conflitos de interesse (ABIRACHED, 2011).

As relações sociais e políticas na localidade em comento têm refletido assimetrias, disputas e interesses pelo espaço territorial, de tal forma que se pode perceber o uso privilegiado dos instrumentos de ordenamento ambiental e territorial em trindade (ABIRACHED, 2011).

Para Abirached (2011, p. 87), apesar do discurso da necessidade de integração e planejamento integrado entre os órgãos municipais, estaduais e federais, na prática predominam o tratamento setorial e interesses privados privilegiados por uma burocracia estatal, que na falta de acordos políticos que compatibilizem tais interesses, obstaculizam a integração e complementaridade dos instrumentos de gestão territorial e ambiental.

O Município de Paraty, com um território de $928 \mathrm{~km}^{2}$, possui aproximadamente 37.575 habitantes e a ampliação dos portos, construção da usina nuclear de Angra III, a crescente exploração de petróleo e gás natural na baía da Ilha Grande tendem a incrementar essa população, bem como a demanda por novas áreas para ocupação do solo na região. E como a área costeira ocupada e utilizada pelos Caiçaras de Trindade é de grande relevância para os setores do turismo e imobiliário esse problema tende a ser agudizado sobre eles (ABIRACHED, 2011, p. 13-40). 
É nesse cenário de assimetrias dessas relações sociais que surge a preocupação com os direitos humanos, justiça social e cidadania dos Caiçaras da praia de Trindade, com sua reivindicação do reconhecimento do direito de continuar a ser-quem-são, no lugar que fazem-e-os-faz-reciprocamente, e cuja trajetória histórica parece insinuar a interconexão entre as dimensões culturais, políticas e econômicas no reconhecimento estatal de direitos e delineamento de políticas públicas.

\section{APROXIMAÇÕES AO CASO CONCRETO PELA TEORIA DO RECONHECIMENTO}

Importa justificar aqui as reflexões desenvolvidas nesse estudo sobre a Teoria do Reconhecimento do filósofo alemão Axel Honneth. O caso concreto dos Caiçaras da praia de Trindade insinua a importância das relações afetivas entre sujeitos, e do afeto ao lugar na produção social de significados, e dessa forma, dos sentimentos morais e padrões culturais capazes de articulação de exigências comunicativas e de reconhecimento jurídico.

Embora Honneth não tenha pensado na realidade empírica do terceiro mundo ao formular sua teoria, percebe-se nela a possibilidade de melhor dialogar com o grau de assimetria social e as experiências afetivas e morais dos Caiçaras da praia de Trindade.

É nessa perspectiva teórica que ganha relevância metodológica a necessidade de investigação empírica dos sentimentos de injustiça e das experiências de desrespeito, para análise do processo de formação das identidades individuais e coletivas dos Caiçaras da praia de Trindade, a partir de um contexto prévio de relações de reconhecimento e da reconstrução lógica das experiências do desrespeito, e do potencial desencadeamento de lutas sociais por reconhecimento e dignidade. $\mathrm{O}$ que por questões de viabilidade não pode ser pretendido nesse estudo, haja vista não ter sido possível a realização de pesquisa de campo.

Objetiva-se aqui, por isso, somente discutir as reivindicações dos Caiçaras da praia de Trindade, não apenas pela perspectiva do reconhecimento jurídico estatuído pela ordem vigente, mas pelos sentimentos e expectativas morais que lhes tem sido culturalmente ignorados, tracejados, segundo material secundário de pesquisa selecionado.

Dando cumprimento ao objetivo formulado, pretende-se reconstruir os principais argumentos da Teoria do Reconhecimento de Axel Honneth, que se 
prestam mais a dialogar com o caso concreto em comento e, dessa forma, contribuir com sua melhor compreensão.

Honneth (2003) identificou, em Hegel, distintos meios de reconhecimento intersubjetivo, que vão além do reconhecimento meramente cognitivo kantiano, e se estendem ao afetivo, jurídico e à solidariedade, a partir de vínculos éticos, que com eles se movem. Uma intersubjetividade prática de um ethos concreto, resultante de três distintos padrões de reconhecimento universais que se distinguem da totalidade concreta de todas as formas particulares de vida, na qualidade de elementos estruturais para o vínculo ético entre os sujeitos e sua autorrealização bem-sucedida (HONNETH, 2003).

E, procurou superar as dificuldades que Hegel encontrou para descrever os conteúdos normativos de um processo de socialização do qual pudessem resultar simultaneamente tanto o crescimento de vínculos éticos da comunidade quanto da liberdade individual, recorrendo, na psicologia social de Mead, a uma concepção intersubjetivista da autoconsciência humana, que ao incluir no processo de formação da identidade prático-moral do sujeito uma tensão intrapsíquica entre vontade global internalizada e as pretensões da individuação, percebe que da necessidade psíquica de autorrealização bem-sucedida das exigências por novas formas de reconhecimento social, que afluem criativamente das subjetividades nas reações involuntárias aos desafios sociais, depende em princípio o assentimento de todos os membros da sociedade, o que representa as linhas gerais de um conflito que deve explicar o desenvolvimento moral tantos dos indivíduos como das sociedades (MEAD apud HONNETH, 2003).

Ao resgatar a categoria hegeliana de "reconhecimento", renovando-a sob as premissas da psicologia social de Mead, esse autor consegue construir um sistema de eticidade alicerçado no reconhecimento intersubjetivo da particularidade de todos, num "movimento de reconhecimento" com etapas de reconciliação e de conflito, no curso histórico-universal do "vir-a-ser da eticidade" e de crescimento das capacidades do eu. E perceber a realidade social do conflito como também estruturante da intersubjetividade e, dessa forma, as lutas por reconhecimento e dignidade como força motriz da intersubjetividade na qual se movem e se constituem as identidades individual e coletiva (HONNETH, 2003).

Daí, em Honneth (2003), é possível perceber a categoria "reconhecimento" como experiência moral intersubjetiva de confirmação de pretensões normativas inscritas nas esferas de relações afetiva, jurídica e de estima social, sob os critérios da auto-realização prática individual e de uma 
eticidade pós-tradicional (Mead Apud HONNETH, 2003). Essas três formas universais (padrões) de reconhecimento ocorrem em níveis distintos (amor, direito e estima social), mas interligados, aos quais devem corresponder respectivamente as dimensões morais da estrutura intersubjetiva da personalidade, em seu potencial particular de desenvolvimento moral e suas formas de autorrelação individual possibilitada (HONNETH, 2003, p. 159)

$\mathrm{Na}$ esfera das relações afetivas (amor e amizade), o indivíduo humano (objeto de reconhecimento) é reconhecido em suas carências concretas (natureza carencial e afetiva) com a dedicação afetiva do parceiro de interação (modo de reconhecimento afetivo intuitivo), o que lhe permite alcançar a autoconfiança $\mathrm{e}$ autonomia (forma de autorrelação prática individual) indispensáveis, não apenas para a articulação de suas próprias carências e de seus projetos de realização pessoal, mas com potencial evolutivo para o desenvolvimento de todas as outras dimensões morais da estrutura intersubjetiva de sua personalidade, na qualidade de pressuposto psíquico para: confiança no mundo social, capacidade cognitiva de intuir-o-outro-em-si-mesmo e generalizá-lo em suas carências e necessidades, bem como de reconhecer capacidades e propriedades que o outro desenvolveu (HONNETH, 2003, p. 59-60).

Para Honneth (2003) somente as relações de reconhecimento situadas nas esferas social e jurídico-moral possibilitam a luta por reconhecimento ganhar contornos de um conflito social, a experiência intersubjetiva do amor situa-se num quadro de interação limitado, que não instrui completamente o sujeito acerca das funções que os direitos intersubjetivamente garantidos devem assumir no contexto da vida social, além de ainda não se encontrar estruturalmente uma tensão que possa suscitar conflitos sociais, o que não falta às formas de desrespeito como a privação de direitos e a degradação de formas de vida, situadas nas esferas do direito e da estima social, respectivamente.

Nas relações intersubjetivas de amor, familiares e de amizade, com a dedicação afetiva (modo de reconhecimento afetivo intuitivo), o indivíduo humano (objeto de reconhecimento) é reconhecido em suas carências concretas, formando-se e desenvolvendo-se a dimensão intersubjetiva carencial e afetiva da personalidade, encadeando uma forma de autoconfiança psíquica e de equilíbrio intersubjetivo entre fusão e delimitação do Ego (HONNETH, 2003).

Dessa forma, na esfera das relações afetivas (amor e amizade), o indivíduo humano (objeto de reconhecimento) é reconhecido em suas carências concretas (natureza carencial e afetiva) com a dedicação afetiva do parceiro de interação (modo de reconhecimento afetivo intuitivo), o que lhe permite 
alcançar a autoconfiança e autonomia (forma de autorrelação prática individual) indispensáveis, não apenas para a articulação de suas próprias carências e de seus projetos de realização pessoal, mas com potencial evolutivo para desenvolvimento de todas as outras dimensões morais da estrutura intersubjetiva de sua personalidade (HONNETH, 2003).

Para Honneth (2003) é aqui que o padrão de reconhecimento do amor toca nas relações de reconhecimento jurídico e da estima social, pois a dimensão moral afetiva da estrutura intersubjetiva da personalidade constitui pressuposto psíquico para estruturação e desenvolvimento da confiança no mundo social, da capacidade cognitiva de intuir-o-outro-em-si-mesmo e generalizá-lo em suas carências e necessidades (reconhecimento de-si-no-outro e de seus direitos), bem como de reconhecer as capacidades e propriedades que o outro desenvolveu (HONNETH, 2003).

Para Honneth (2003), o movimento socializador do reconhecimento jurídico rompe os limites particularistas das relações afetivas por meio de premissas dos princípios morais universalistas (simetria e igualdade) que possibilitam o esvaziamento e formalização daquilo que encontra confirmação intersubjetiva no sujeito singular, e sua incorporação nas normas intersubjetivamente reconhecidas de uma sociedade.

Nesse sentido, Marshall demonstrou em seu esquema histórico de ampliação dos direitos individuais fundamentais, obtidos por luta social, que o princípio da igualdade embutido no direito moderno teve por consequência que o status de uma pessoa de direito pôde ser ampliado tanto no aspecto objetivo, em conteúdos materiais, como no aspecto social, sendo transmitido a um número sempre crescente de grupos, até então excluídos ou desfavorecidos, os mesmo direitos que a todos os demais membros da sociedade (MARSHALL apud HONNETH, 2003, p. 190-193). Mas, também que, somente nas situações históricas excepcionais em que os próprios grupos excluídos atingidos debatem publicamente a privação de direitos fundamentais, sob o ponto de vista de que, com o reconhecimento denegado, se perderam também as possibilidades de autorrespeito individual, vem à superfície da linguagem o significado psíquico que o reconhecimento jurídico possui para o autorrespeito de grupos excluídos, que a tolerância ao subprivilégio jurídico conduz a um sentimento paralisante de vergonha social, do qual só o protesto ativo e a resistência poderiam liberar (MARSHALL apud HONNETH, 2003, p. 198).

Esses direitos ligados até então ao status, só se tornaram uma classe separada de direitos básicos universais quando finalmente, às exigências de 
igualdade de grupos excluídos não podia mais se contrapor nenhum argumento convincente (HONNETH, 2003, p. 191).

$\mathrm{Na}$ esfera das relações jurídicas (modo de reconhecimento cognitivo/ intelectivo), a pessoa (objeto de reconhecimento) é reconhecida como pessoa de direito abstrata, moralmente imputável e autônoma (imputabilidade moral), e em suas pretensões jurídicas individuais, por todas as demais, mediante a experiência adjudicação de direitos (respeito cognitivo), o que lhe permite alcançar autorrespeito (autorrelação prática individual) e é indispensável, para superar a percepção desses direitos como signos anonimizados de um respeito social, como potencial evolutivo para generalização e materialização de novos direitos sob as premissas de uma moral pós-convencional (HONNETH, 2003).

Dessa forma, o reconhecimento jurídico contém em si um potencial moral capaz de ser desdobrado através de lutas sociais, na direção de um aumento tanto da universalidade quanto de sensibilidade para os contextos sociais. Mas só com o desacoplamento entre as pretensões jurídicas individuais e as atribuições sociais ligadas ao status se origina o princípio da igualdade universal, que daí em diante vai submeter toda ordem jurídica ao postulado de não admitir mais, em princípio, exceções e privilégios (HONNETH, 2003).

Para Mead, ainda que o sujeito partilhe as capacidades vinculadas a todos os seus concidadãos, ele não poderia se referir positivamente ainda, como pessoa de direito, àquelas propriedades suas em que ele distingue justamente de seus parceiros de interação, precisaria ainda de uma forma de reconhecimento mútuo que propiciasse a confirmação a cada um não apenas como membro de uma coletividade, mas também como sujeito biograficamente individuado (HONNETH, 2003).

A autocompreensão cultural de uma sociedade predetermina critérios pelos quais se orienta a estima social das pessoas, já que suas capacidades e realizações são julgadas intersubjetivamente, à medida que cooperem na implementação de objetivos e valores sociais culturalmente definidos (HONNETH, 2003, p. 200). E o valor conferido às diversas formas de autorrealização e a maneira como se definem as propriedades e capacidades correspondentes, dependem das interpretações que predominam historicamente acerca das finalidades sociais, e correspondem, em grande parte, à identidade coletiva do próprio grupo (HONNETH, 2003, p. 206-208).

Mas, é a concordância no objetivo prático, predominante nessas relações intragrupais, que gera de súbito um horizonte interpretativo de valores no qual cada um aprende a reconhecer em igual medida o significado das capacidades 
e propriedades do outro. Tais formas de interação assumem nesses casos normais o caráter de relações solidárias: "relações nas quais todo membro se sabe estimado por todos os outros na mesma medida, e os sujeitos tomam interesse reciprocamente por seus distintos modos de vida, já que eles se estimam entre si de maneira simétrica" (HONNETH, 2003, p. 209-210). Daí resulta, para Honneth (2003, p. 200), a importância social de um pluralismo cultural, já que as condições culturais de simetria social dependem, sobretudo, de um pluralismo axiológico sobre as concepções de bem-viver, e de estima e valoração social.

Nessas relações, o respeito de cada pessoa pela particularidade biográfica de toda outra, e de suas realizações, é necessariamente concomitante com a abertura das concepções axiológicas sociais para distintos modos de autorrealização pessoal. Pois, essas relações não despertam apenas tolerância para com a particularidade individual de outra pessoa, mas também o interesse afetivo por essa particularidade, do que resulta uma imediata abertura exegética fundamental de todos os horizontes sociais de valores, já que, na medida em que o sujeito cuida ativamente de que aquelas propriedades estranhas a ele possam se desdobrar, os objetivos até então incomuns passam a ser realizáveis (HONNETH, 2003).

Por esse mecanismo da estima simétrica, e pelo fardo de acontecimentos coletivos, como a guerra, Honneth (2003) procura explicar a transformação estrutural, dos mecanismos de estima para solidariedade social, fundando relações espontâneas de interesse solidário para além dos limites sociais: "origina-se num átimo uma nova estrutura de valores que permite mutuamente aos sujeitos estimar o outro por realizações e capacidades que antes não tiveram importância social":

Assim, Honneth (2003) delineia, em sua teoria do reconhecimento, a ideia de um conceito formal de uma eticidade pós-tradicional e democrática, que só pode nascer das finalidades partilhadas em comum, cujas condições intersubjetivas da integridade pessoal e de uma vida bem-sucedida migram para as condições normativas de um índice histórico, determinada pelo nível de desenvolvimento dos padrões de reconhecimento então vigentes, e cujas exigências só podem ser cumpridas em longo prazo, quando ocorrem mudanças culturais que acarretam uma ampliação radical das relações de solidariedade, que devem coexistir, em todo caso, com os outros dois padrões de reconhecimento do amor e do direito (HONNETH, 2003). 
Sobre a experiência moral do sentimento de desrespeito correspondente à denegação do reconhecimento pretendido pelo sujeito, esse autor explica que do entrelaçamento interno de individualização e reconhecimento resulta a vulnerabilidade da autoimagem normativa particular de cada ser humano, que depende sempre da possibilidade de um resseguro constante no outro. A experiência moral do desrespeito, ancorada nas vivências afetivas dos sujeitos humanos, tende a proporcionar, no plano motivacional de um processo de formação e desenvolvimento prático-moral das identidades individuais e coletivas, o impulso para luta moral por reconhecimento (HONNETH, 2003).

Assim, numa consideração sistemática das formas de desrespeito, ao perceber que elas podem tornar experienciável para os atores sociais, na qualidade de um equivalente negativo, as correspondentes relações de reconhecimento denegado, Honneth (2003, p. 157-211) distingue-as, tanto em suas possíveis manifestações e potenciais lesivos. Para ele, nas relações do amor, inscrevem-se a forma de desrespeito dos maus-tratos e violação, que ameaçam a integridade pessoal (liberdade e autonomia) e a capacidade de confiança (no outro e no mundo social). Nas relações jurídicas, inscrevem-se as formas de desrespeito da privação de direitos e exclusão, que ameaçam a integridade social. E nas relações de solidariedade social, inscrevem-se a degradação e ofensa aos valores culturais, que ameaçam a dignidade humana.

Hegel propõe um contramodelo estrutural social de "luta por reconhecimento", que ao invés de constelações de interesses e concorrência por bens escassos, toma como ponto de partida os sentimentos de desrespeito e injustiça experimentados pelos grupos sociais, que servem de impulso moral para ações coletivas que visam estabelecer, institucional e culturalmente, formas ampliadas de reconhecimento recíproco, por meio dos quais ocorre a transformação normativamente gerida das sociedades (HONNETH, 2003).

Esse modelo hegeliano de conflito inspirou Honneth (2003), em sua teoria do reconhecimento, a um modelo analítico de "luta por reconhecimento" que, partindo das condições intersubjetivas de integridade pessoal e dos sentimentos morais coletivos, atribui ao surgimento e ao curso das lutas sociais as ações dos grupos sociais perante as experiências morais de denegação do reconhecimento jurídico ou social (HONNETH, 2003, p. 261). Que procura explicar as lutas sociais a partir da dinâmica das experiências morais, instruindo acerca da lógica moral dos conflitos sociais, numa gramática historicamente cambiante de reconhecimento e de desrespeito, na qual está inscrita o nexo entre desrespeito moral e luta social (HONNET, 2003). 
Para Honneth (2003), se esse modelo analítico de conflito, baseado na teoria do reconhecimento, não puder substituir precisamente o modelo utilitarista, já que a princípio permaneceria a questão empírica de saber até que ponto um conflito social segue a lógica da persecução de interesses ou a lógica da formação da reação moral, pode complementá-lo e retificá-lo, já que mesmo nos conflitos sociais por poder, é possível se remontar às experiências morais anteriores de infração das regras implícitas de reconhecimento recíproco (HONNET, 2003).

Concordando aqui com Georg Simmel, para quem as relações de estima social estão acopladas de forma indireta com os padrões de distribuição de renda, Honneth $(2003$, p. 208) afirma que os confrontos econômicos também pertencem constitutivamente a essa forma de luta por reconhecimento, e os conflitos sociais, mais do que a demanda por redistribuição de bens materiais, colocam em pauta a luta pela dignidade humana, pelo reconhecimento do valor das diversas culturas e modos de vida.

Além disso, para Honneth (2003), permaneceria em aberto, num nível descritivo, uma pré-decisão a favor de formas não violentas ou violentas de resistência, se são pelos meio práticos da força material, simbólica ou passiva que os grupo sociais procuram articular publicamente os desrespeitos e as lesões vivenciados como típicos a reclamar contra eles (HONNETH, 2003, p. 257).

Assim, caberia ao momento da "luta" no movimento de reconhecimento não só uma função negativa e transitória, mas também a função positiva de oferecimento das condições sociais de possibilidade à ampliação das relações sociais de reconhecimento vigentes (HONNETH, 2003).

E, nem todas as esferas de luta por reconhecimento contêm em si, o tipo de tensão moral capaz de por em marcha os conflitos sociais, já que o amor não contém experiências morais que possam levar por si só a formações de conflitos sociais, vez que suas experiências não se deixam generalizar para além do quadro de interação limitado de uma relação primária, chegando a um ponto em que eles podem se tornar a base de um movimento coletivo, tal como nas esferas de luta por reconhecimento do direito e da estima social que dependem de critérios socialmente generalizados (HONNETH, 2003).

Dessa forma, para Honneth (2003), a todo ato coletivo de resistência e rebelião poderia ser atribuído, segundo sua origem, a um quadro invariante de experiências morais de sentimentos de sentimentos de desrespeito e injustiça partilhados em comum, e teria a dupla função reativa de exigência do atendimento às expectativas sociais morais, bem como nova forma de autoidentificação coletiva. 
Assim, da proposta de uma "teoria do reconhecimento", é possível extrair critérios normativos das exigências morais das experiências de desrespeito e injustiça presentes nas lutas sociais por reconhecimento e dignidade, de determinada cultura e determinado tempo histórico, e pela qual seria possível justificar as finalidades da redistribuição, por meio de um quadro analítico mais abrangente das categorias do reconhecimento social, podendo começar, inclusive, em nossa atualidade, pelo status social definido por uma prioridade estrutural dos imperativos capitalistas de valorização (HONNETH, 2003).

Mas todos esses argumentos levam a crer que, ao recorrer à tradição filosófica hegeliana de luta por reconhecimento, Honneth parece ter incorrido na mesma tendência cultural de percepção homogeneizante dos sistemas sociais de cognição e interação (amor, direito e estima social).

E, o caso concreto de Trindade tem demonstrado que também o afeto dos Caiçaras ao lugar tem sido particularmente capaz de produção social de significados, modulação de sua racionalidade instrumental e exigências morais de reconhecimento dessa relação afetiva em particular, como impulso moral às suas concepções de bem-viver e pretensões jurídicas.

O que talvez possa explicitar ou contribuir com a percepção, no âmbito da teoria do reconhecimento, de que, por um lado, não apenas as relações afetivas entre sujeitos, mas também as relações afetivas com o ambiente natural possam produzir intersubjetividade de sentimentos morais, e por outro, também os conflitos e as contingências por compartilhamento e conservação de um local e seus recursos, possam ser capazes de ampliar o interesse afetivo pelas capacidades contributivas e particularidades do outro.

\section{CONSIDERAÇÕES FINAIS}

Os Caiçaras da praia de Trindade constituem um grupo social, que num contexto histórico de ciclos econômicos de exploração no Brasil, migrou para a localidade da praia da trindade, Paraty/RJ, onde, e, a partir das especificidades daquele ambiente natural, inovou na produção material e organização social, de tal forma que resultou numa mudança estrutural nos sistemas de cognição e interação social, diferenciando-se culturalmente por práticas, saberes e racionalidade instrumental, adaptados ao lugar e transmitidos às gerações seguintes pela oralidade.

Característica que parece demonstrar a capacidade contributiva do lugar (ambiente natural) não apenas na produção intersubjetiva de afetos, concepções 
de bem-viver, e da própria racionalidade instrumental, mas também, por sua relevância na construção e transformação de sistemas de cognição e a linguagem, mas também nos possíveis efeitos sobre os processos comunicativos e de interação social.

Mas que por outro lado, no contexto e realidade dos Caiçaras de Trindade, também parece evidenciar a importância da forma cultural com a qual se é possível perceber o significado das reivindicações dos Caiçaras da praia de Trindade por reconhecimento do direito de continuar a ser-quem-são e permanecer no lugar que fazem-e-os-faz-reciprocamente, não apenas pela perspectiva do reconhecimento jurídico estatuído pela ordem vigente, mas, pela valorização das relações afetivas entre os Caiçaras e desses àquele lugar.

Contexto em que ganhou relevância a teoria honnethiana do reconhecimento, para a qual, as relações afetivas entre sujeitos (amor e estima social) se constituem no alicerce psíquico para estruturação da capacidade da estrutural moral intersubjetiva da personalidade de reconhecimento cognitivo do direito.

Também não foi possível objetivar nesse estudo, na dimensão metodológica da teoria do reconhecimento, a investigação empírica dos sentimentos de injustiça e das experiências de desrespeito, para análise do processo de formação das identidades individuais e coletivas dos Caiçaras da praia de Trindade, a partir de um contexto prévio de relações de reconhecimento e da reconstrução lógica das experiências do desrespeito, e do potencial desencadeamento de lutas sociais por reconhecimento e dignidade.

Mas, foram realizadas aproximações teóricas ao contexto intercultural de Trindade, por meio da teoria do reconhecimento, com vistas numa maior compreensão das reivindicações dos Caiçaras da praia de Trindade, não apenas pela perspectiva do reconhecimento jurídico estatuído pela ordem vigente, mas pelos sentimentos e expectativas morais que lhes tem sido culturalmente ignorados.

Para Honneth (2003), em sua Teoria do Reconhecimento, as condições de simetria social e os padrões de reconhecimento moral (que vão além do cognitivo do direito e se estendem ao afetivo nas esferas do amor e da estima social), tendem a ser determinados pelo grau de pluralismo axiológico sobre as concepções de bem-viver e das capacidades contributivas aos objetivos sociais definidos, em determinada cultura e tempo histórico.

Tanto as experiências morais intersubjetivas de confirmação de pretensões culturais do comportamento do outro (reconhecimento moral) nas esferas do 
amor, direito e estima social, como, na qualidade de equivalente negativo dessas relações, as correspondentes experiências de pretensões denegadas (desrespeito e injustiça), experienciadas pelos atores sociais, estão inscritas exigências morais normativas (gramática dos sentimentos morais), capazes não apenas de gerar intersubjetividade, como de por em marcha ações coletivas que visam estabelecer, institucional e culturalmente, formas ampliadas de reconhecimento recíproco então vigentes, nas relações do direito de estima social.

Por isso, a gramática moral na qual estão inscritas as experiências de desrespeito e injustiça poderia também ser mobilizada de forma crítica para a tarefa de superação das tensões e conflitos interculturais, pela via do interesse afetivo aos sentimentos e racionalidades instrumentais, que poderiam ser apreendidos por uma operação afetiva de reconhecimento das expectativas morais do outro, que em nossa língua poderia ser aproximadamente conceituada como empatia, agora também contributiva ao modelo de intersubjetividade pelo qual se fundamentam a moral pós-convencional e a eticidade formal, capazes de ampliação radical das relações sociais de reconhecimento vigentes.

Pela aproximação crítica, também o afeto dos Caiçaras da praia de Trindade ao lugar parece explicitar ou contribuir com a percepção, no âmbito da teoria do reconhecimento, de que, por um lado, não apenas as relações afetivas entre sujeitos, mas também as relações afetivas com o ambiente natural possam produzir intersubjetividade de sentimentos morais, e por outro, também os conflitos e as contingências por compartilhamento e conservação de um local e seus recursos, possam ser capazes de ampliar o interesse afetivo pelas capacidades contributivas e particularidades do outro.

Dessa forma, em sociedades multiculturais a justiça social parece ser diretamente proporcional aos padrões e níveis culturais das relações de reconhecimento moral vigentes entre sujeitos, delimitados pela pluralidade de orientações axiológicas sobre bem-viver e capacidades contributivas sociais. Mas, se o afeto ao lugar tem sido particularmente capaz de produção social de significados, modulação da racionalidade instrumental e exigências morais de reconhecimento dessa relação afetiva em particular, como impulso moral às concepções de bem-viver e pretensões jurídicas, como o explicitado no caso dos Caiçaras da praia de Trindade, então, essa necessária abertura exegética parece também depender do interesse afetivo pelas relações dos sujeitos com o ambiente natural.

O próprio direito precisa passar a ser percebido como mais uma instância de mediação entre a racionalidade instrumental e o mundo da vida, ao lado das 
relações afetivas de amor e estima social que constituem o alicerce psíquico para estruturação da capacidade da moral intersubjetiva da personalidade de reconhecimento cognitivo do direito, de forma que os sentimentos morais de desrespeito, injustiça e indignação passam a ser valorizados e a operar como sensores e catalisadores de demandas por reconhecimento jurídico e transformações sociais.

E muda também o conceito de cidadania, vez que, se por um lado, a luta social por pretensões morais de reconhecimento e dignidade passa a ser percebida como mais um momento social normativo, igualmente capaz, de produção de significados e ampliação das relações sociais culturalmente vigentes, por outro lado, cria-se a expectativa aos diferentes atores e grupos culturais de superação de tensões interculturais pela mobilização crítica da gramática moral inscrita nas experiências de desrespeito e injustiça.

\section{REFERÊNCIAS}

\section{ABIRACHED, Carlos de Andrade. Ordenamento territorial e áreas} protegidas: conflitos entre instrumentos e direitos de populações tradicionais de Ubatuba-Paraty. Brasília: UnB, 2011.

ADAMS, Cristina. As populações caiçaras e o mito do bom selvagem: a necessidade de uma nova abordagem interdisciplinar. Revista de Antropologia, São Paulo, v. 43, n. 1, 2000.

BARDIN, Laurence. Análise de conteúdo. São Paulo: Ed. 70, 2011.

BRASIL. Supremo Tribunal de Justiça. Acórdão RE n. 1.091.438 - RJ (2008/0212224-9). Ação de usucapião pela imprescritibilidade das áreas suscitadas pelos Caiçaras de Trindade. Disponível em: $<$ https:// ww2.stj.jus.br/revistaeletronica/

Abre_Documento.asp?sLink $=$ ATC \&sSeq $=1079899$

$5 \&$ sReg $=200802122249 \&$ sData $=20100803 \&$ sTipo $=5 \&$ form ato $=$ PDF $>$. Acesso em: 5 jul. 2013.

BRASIL. Decreto Federal n. ${ }^{0}$ 68.172/71. Criou o parque nacional da Serra da Bocáina. Disponível em: <http://www.planalto.gov.br/ccivil_03/ decreto/1970-1979/D68172.htm>. Acesso em: 5 jul. 2013. 
BRASIL. Decreto Federal n. ${ }^{\circ}$ 89.242/83. Criou a área de proteção ambiental de Cairuçu - APA Cairuçu. Disponível em: <http:// www.planalto.gov.br/ccivil_03/decreto/1980-1989/D89242.htm>. Acesso em: 5 jul. 2013.

BRASIL. Lei 9.985/00. Institui o sistema nacional de unidades de conservação da natureza. Disponível em: $<\mathrm{http}$ ://www.planalto.gov.br/ ccivil_03/leis/L9985.htm>.Acesso em: 5 jul. 2013.

BRASIL. Ministério do Meio Ambiente. Plano de Manejo da APA Caiçuru: encarte II - caracterização sócio-econômica. Brasília, 2004.

BRASIL. Ministério do Meio Ambiente. Portaria n. ${ }^{\circ}$ 349/06. Criou o mosaico de unidades de conservação da região da Serra da Bocáina no âmbito do Corredor de Mosaicos da Serra do Mar. Disponível em: $<$ http:// www.bocaina.org.br/images/BOCAINA/documentos/

mosaicobocaina_portaria349criamosaicobocaina2006.12.11.pdf $>$. Acesso em: 5 jul. 2013.

CONTI, Bruna Ranção. Proteção da natureza e qualidade de vida em Trindade (Paraty - RJ): para entender o ecoturismo no Parque Nacional da Serra da Bocáina. 2011. Dissertação (Mestrado em Psicossociologia de Comunidades e Ecologia Social) - Universidade Federal do Rio de Janeiro, Instituto de Psicologia, Rio de Janeiro, 2011.

DIEGUES, Antônio Carlos. O mito moderno da natureza intocada. 6. ed. São Paulo: HUCITEC, 2008.

HERCULANO, Selene. Em busca da boa sociedade. Niterói: EdUFF, 2006.

HONNETH, Axel. Luta por reconhecimento: a gramática moral dos conflitos sociais. São Paulo: Ed. 34, 2003.

IRVING, Marta de Azevedo. Áreas protegidas e inclusão social: construindo novos significados. Rio de Janeiro: Fundação Bio-Rio, 2006. 
LOBÃO, Ronaldo. Cosmologias políticas do neocolonialismo: como uma política pública pode se transformar em uma política do ressentimento. Niterói: Ed. Universidade Federal Fluminense, 2010.

MARCÍLIO, Maria Luiza. Caiçara: terra e população. estudo de demografia e da historia social de abatida. 2. ed. São Paulo: EDUSP, 2006.

MEDEIROS, Rodrigo; IRVING, Marta de Azevedo; GARAY, Irene. Áreas protegidas no Brasil: interpretando o contexto histórico para pensar a inclusão social. In: IRVING, Marta de Azevedo. Áreas Protegidas e Inclusão Social: construindo novos significados. Rio de Janeiro: Fundação Bio-Rio, 2006.

Artigo recebido em: 24/10/2013 Aprovado para a publicação em: 18/11/2013

Como citar: FERRAZ, Andre Mendes da Fonseca; LOBÃO, Ronaldo Joaquim Silveira. O Caso dos caiçaras da Praia de Trindade: Aproximações honnethianas para uma perspectiva intercultural de direitos humanos, justiça social e cidadania. Revista do Direito Público, Londrina, v.8, n.3, p.103-130, set./dez. 2013. DOI: 10.5433/1980-511X.2013v8n3p103. 